This article has been scanned by iThenticat No plagiarism detected

Volume 3, Issue 6, December 2021

p. $12-29$

\title{
VERBAL SEXUAL HARASSMENT AMONG STUDENTS IN NAZARETH AND MECHANISMS TO REDUCE IT, FROM THE POINT OF VIEW OF SPECIALITS AND COUNSLERS
}

http://dx.doi.org/10.47832/2757-5403.6-3.2

\begin{abstract}
:
The study aimed to identify the reality of verbal sexual harassment in the cyberspace of Tawjihi students from the point of view of specialists and counselors. The researcher used the qualitative approach, and the study population consisted of a random sample of 30 specialists and counselors. The researcher used the interview as a study tool, which consisted of two (2) questions. The first paragraph includes questions about the spread of the phenomenon, consisting of (4) areas (definition, spread, causes, technology), and the second paragraph on the mechanism of reducing it, consisting of (6) areas (education, family parents, school curriculum, authority institutions, victims of the phenomenon, groups of the influence). After using the interviews and analyzing them, the results of the study showed that the estimates of the sample members have linked education and verbal sexual harassment, so that the relationship was inverse, that is, the greater the awareness of the lack of verbal sexual harassment. in favor of females. This study also dealt with the impact of the Corona epidemic on the spread of this phenomenon in a very wide way, in the years 2018-2020.

The recommendations came to the need to monitor budgets by the authority, to hold courses and workshops throughout the year, to establish an educational and deterrent committee, to include the subject of verbal sexual harassment in the school curriculum, to monitor its implementation throughout the year, and to listen to the reactions of students and parents after the end of the first semester of the year, It is the application of education curriculum of sexual harassment over the network.
\end{abstract}

\footnotetext{
${ }^{1}$ Dr. , Latin Patriarchal Schools - Yafa Nazareth and the village of Rama , Palestine, khouryn7@gmail.com, https://orcid.org/0000-0002-1266-634X
}

Copyright $(\mathcal{C}$ Published by IJHER Journal, www.ijherjournal.com Rimar Academy, Fatih, Istanbul, 34093 Turkey

All rights reserved 
Key words: Sexual Harassment, Educational Specialists, Students, Cyberspace, Family, School, Budgets. (220 Word).

\section{Introduction}

Recently, we have seen an increase in cases of sexual violence against men and women across the network. Virtual space is a state in which people are allowed to commit immoral and abusive acts, which they would not necessarily dare to do in a face-to-face encounter. This sensitive and bold topic is mostly avoided by researchers, as it contradicts the traditions and values of society. Especially the Arab community. This research also suffers from a lack of sources and books that clearly dealt with it.

This is due first and foremost to the anonymity of the harasser, which allows the surfer to impersonate another "impersonator" and display information without being exposed to it. This creates a feeling that the offender will not have to stand trial and pay for his actions ostensibly, according to the law (Zuri, 2020).

Physical distance and the absence of physical encounter prevents the offender from seeing the injury and being exposed to the consequences of his actions, making it easier for him to conscientiously carry out harassment and assault.. Moreover, in certain places on the Internet, prevailing rules of conduct have been formed that give legitimacy to surfers to write offensive things, with the feeling that these is the usual way to behave in this space.This phenomenon violates two main rights:

The first is the right to life and security, which states that every human being has the right to protect his life and his life and security. This right is reflected in the problem you have chosen, because network sexual assault constitutes and causes harm to the lives of victims and their mental and even physical security (Green,2020)).

Second, the right to dignity, and in particular the right to privacy. This right states that there are rules of respect that change from place to place, and from time to time, among human beings, and they must be guarded.

Among other matters, rules have been established that prove that no one should and may not have intercourse with anyone except with his permission, and that he does not bother and harm people. Privacy states that each person has a private space physical and virtual under his control. It is clear, then, that this infection is an insult to privacy and sexual life online, and a flagrant violation of these rights. In addition, network sexual assault constitutes a flagrant violation of the rule of law principle, which states that law in a democracy is above all else (Keren, 2017).

The citizens of the country decided that they were willing to harm their freedom, in order to maintain a certain social order, so they established a system of laws. Sexual assault violates the laws of the state, and often the perpetrators are not caught, therefore this phenomenon is painful, and leads to a breach of the principle of the rule of law.

I chose this problem because we are witnessing its transcendence and disturbing spread in society, and because there is no satisfactory solution to it until today. I believe that the solution to this problem lies in educating young people properly and better, and that this problem concerns all of us, whether we have been hurt or know someone who has been hurt by it (Alon, 2019). 
As part of the work, I chose to implement a project on the phenomenon of sexual verbal violence in the Internet and the use of technology, to do an in-depth study of the phenomenon through theoretical research - reviewing the literature, and through practical research by interviewing 30 (thirty) people.

After the study, a discussion was conducted and conclusions were drawn from it, from which many ideas were drawn: in order to solve this problem. I chose an idea that seemed to me the most appropriate and effective in light of the research that had been done and implemented it. You will learn about the research that you have done comprehensively, as well as the solution that has been suggested and will be done.

\section{The Study Problem}

Recently, we have seen an increase in cases of sexual violence against men and women across the network. Virtual space is a state in which people are allowed to commit immoral and abusive acts, which they would not necessarily dare to do in a face-to-face encounter. This sensitive and bold topic is mostly avoided by researchers, as it contradicts the traditions and values of society. Especially the Arab community. This research also suffers from a lack of sources and books that clearly address it.

It is common knowledge that society, especially the Arab, has values, principles and customs that he is proud of, practices them, preserves them, and stands as an impenetrable barrier to harm. It is clear from the above that the issue of verbal sexual harassment over the network is a difficult and thorny issue.

The position of society and state institutions on sexual violence in the network. It is an issue of citizens, social and economic (January, 2018), an immediate solution that requires a solution. Stemming from the corruption of the authority, and spreading without stopping, and affecting the right to dignity, the right to privacy and the right to a good reputation, as we have recently witnessed the spread of cases of sexual violence against men and women through the network. Space allows, (the default mode of people) to commit immoral and abusive acts, which they would not dare to do in physical space, face to face. return this to:

First and foremost to anonymity, which allows the browser to impersonate an unidentified person, after viewing information without being exposed. This creates a feeling that the offender will not have to pay the price according to the law. Additionally, physical distance and the lack of an actual encounter prevents the offender from seeing the injury. The widespread silence of the victims and of both sexes calls for a blatant discussion of this problem.

Given the importance of the subject and the danger of avoiding it, and not confronting it by the officials, the political level that draws and sets the educational plan, and then the implementing level, the educational specialists and counselors. The field is crying out in order to achieve the declared goals before it is too late and the problem escalates.

Based on the network of key concepts shown in the introduction, the problem is embodied in the following question: 
What is the reality of verbal sexual harassment among high(Tawjihi) students in Nazareth from the point of view of educational specialists and counselors?

\section{Study questions}

The study attempts to answer a set of central questions:

The first question: What is the reality of verbal sexual harassment in Nazareth from the point of view of educational specialists and counselors?

The second question: What are the causes of verbal sexual harassment among Tawjihi students in Nazareth from the point of view of specialists and counselors?

The third question: What are the effects of verbal sexual harassment among Tawjihi students in Nazareth from the point of view of specialists and counselors?

Fourth question: What are the proposed mechanisms to reduce verbal sexual harassment among Tawjihi students in Nazareth from the point of view of specialists and counselors?

\section{Objectives of the study}

1- Recognizing the reality of verbal sexual harassment among high (Tawjihi) students in Nazareth from the point of view of specialists and counselors.

2- Identifying the causes of verbal sexual harassment among Tawjihi students in Nazareth from the point of view of specialists and counselors.

3- Recognizing the effects of verbal sexual harassment among Tawjihi students in Nazareth from the point of view of specialists and counsellors.

4- The aim of this study is to see the reality of harassment, if any. And what is its problem? Because it concerns society as a whole, and Tawjihi students in particular. Find out what its dimensions and repercussions are on the generation born with the Internet. As well as how educational specialists and counselors deal if there is harassment, and the search for mechanisms to reduce this phenomenon from the point of view of educational specialists.

Its goal is also to reveal the truth, to show and put the topic on the discussion table, if any, and then to discuss the various aspects and their impact on the Tawjihi students who will be the next society. We also want to know the point of view of educational specialists and counselors on the subject and how to limit the spread of this phenomenon.

\section{Studying importance}

The importance of the study stems from the fact that it confronts the public and society directly, is clear and bold, deals with a sensitive topic that our society did not know before, and our Arab society in particular may be surprised and astonished by the research, and here lies another importance, which is a study of a serious topic that must be at its beginning (i.e. before it escalates) And not at the end. 
As for me as a researcher, the importance of this study lies in:

1 - It is hoped that the results of this study will be submitted to the officials, which will shed light on important points and deliver hot messages to a real and immediate issue according to the interviews.

2 - It is an attempt with scientific tools to reveal the subject of the study.

3- It may be one of the first studies that tackled this topic.

4- It may form a knowledge base for later studies.

\section{Theoretical framework}

This review deals with the phenomenon of sexual violence in cyberspace in Israeli society. In a review to explain the background and causes of the phenomenon, data on its scope, measures to combat it - legislation, education, headquarters and organizations against the phenomenon, as well as pioneering campaigns such as \#MeToo (an international women's movement fighting harassment and sexual assault).

I will discuss the severe consequences of sexual violence, treatment and assistance for victims, as well as an explanation of the most prominent cases of online sexual abuse that have occurred recently in Israeli society and shocked us all.

\section{Sexual violence as a social phenomenon}

There is hardly a woman who has not been sexually assaulted in one form or another, from verbal remarks to physical assault and actual rape, although many do not admit it. The enslavement of women by violence in general, and sexual violence in particular, is one form of sexual expression of oppression in a patriarchal society - a society in which power is concentrated in the hands of men, and power is always in the hands of men (Rooney, 2015).

Sexual assault is often attributed to violence against women only, but this is not the case. The prevailing opinion is that, a man will be pleased to feel that a woman is courting him, especially if she is a woman and attractive. In fact, men are ashamed and afraid to complain about sexual harassment, and this is what happens to them, the infringement of their privacy and dignity is absorbed in silence.

As mentioned, men are also sexually abused, with it is estimated that only $10 \%$ of sexual harassment complaints in the police are made by men. However, the reality on the ground shows that the numbers are much higher, that is, more men are being sexually stalked, based on data provided by the Helpline for Boys and Men Victims of Sexual Abuse (Shefi, 2019). The word Shefi in Hebrew ( שפ"י- שרות פסיכולוגי ייעוצי) means (psychological counseling service centre).

\section{Sexual violence in the (virtual) space}

Over the years, the technological revolution has taken place, one of the most important revolutions in human history. It brought many benefits, such as: ease of communication, globalization and the like, but also 
there are many risks involved, such as violence and cyberbullying. The phenomenon of sexual violence is not a new phenomenon, sex offenders have been here for a long time, but the technological revolution - it has made it easier for them to reach and beat using smart devices (tablets), smartphone, PC, etc., to anyone connected to the Internet and connected to platforms, such as various media such as Social networks (Facebook, Instagram, etc.)

Online sexual crimes are especially dangerous and cruel, due to the ability to harm a large number of victims with the click of a button, that is, quickly and easily. (Association of Assistance Centers for Victims and Victims of Sexual Assault, 2015). The virtual space allows people to commit immoral and abusive acts, which they cannot dare to perform in a face-to-face physical confrontation. This is due to a number of reasons:

First, not revealing the identity of the perpetrator, allowing the surfer to impersonate another person and display information without revealing it. This creates a feeling that the person who hits the web will not have to pay for their actions and pass judgment on them.

* A quarter of women aged 25-34 have experienced network abuse, with two-thirds of women experiencing sexual assault.

- Nearly half of the women who experienced online violence $(49.5 \%)$ reported that they received responses regarding their sexuality regardless of the relevant content (Israel Internet Association, 2014).

- Nearly $11 \%$ of all cyberbullying cases in 2018 constituted sexual harassment.

\section{Previous studies}

ראש הטופסThe researcher found it important to read what writers and other researchers have written on the subject, in order to add to his knowledge what the researchers have reached, compare their ideas and understand their views.

\section{Studies related to the phenomenon of verbal sexual harassment:}

Pressler's study (2015): It aimed to define the phenomenon of verbal sexual harassment via the Internet, as it stated that this phenomenon is free and anonymous and without any restrictions on time and place, so more new opportunities for victimization are created.

ראש הטופס

2. ראש הטופס ראופס

Ronnie Study (2015)

This study aimed to show verbal sexual violence as a social phenomenon via the Internet, and confirmed that sexual violence is a social phenomenon that exists in every human society, where the values of gender inequality and aggressive behavior are accepted. A fact 
that reflects the prevailing social perceptions about the status and role of women in most societies.

Shefi study (2019). This is a Hebrew word (שפ"י- שרות פסיכולוגי ייעוצי) meaning (psychological counseling service center).

The above study aimed to show that sexual assault is often attributed to violence against women only, but this is not the case. The prevailing opinion is that, a man will be pleased to feel that a woman is courting him, especially if she is a woman and attractive. In fact, men are ashamed and afraid to complain about sexual harassment, and this is what happens to them. The infringement of their privacy and dignity is absorbed in silence.

\section{Study of the Association of Centers for Assistance to Victims and Victims of Verbal Sexual Abuse (2015).}

This study dealt with the subject of verbal sexual violence in the (virtual) space, and confirmed that over the years, the technological revolution occurred, and it is one of the most important revolutions in human history. It brought many benefits, such as: ease of communication, globalization and the like, but also there are many risks involved, such as violence and cyberbullying. The phenomenon of sexual violence is not a new phenomenon, and sex offenders have been here for a long time, but the technological revolution - has made it easier for them to reach and beat with devices smartphones (tablets), smartphone, PC, etc., for anyone who is connected to the Internet and connected to platforms, such as various media such as social networks (Facebook, Instagram, etc.).

Study of the Ministry of Interior (2019). This study aimed to examine the reasons for using the network, where the virtual space allows people to commit immoral and abusive acts, which they cannot dare to perform in a face-to-face physical confrontation. This is due to a number of reasons:

First, not revealing the identity of the perpetrator, allowing the surfer to impersonate another person and display information without revealing it. This creates a feeling that whoever hits the web will not have to pay for his actions and pass judgment on them. This study also recommended respecting laws and not breaking them.

Second, the virtual space creates a kind of sense of distance resulting from the lack of physical encounter, and this prevents the offender from being seen.

\section{The study of the Israeli Internet Association (2014).}

This study reported on the percentages of sexual harassment, out of all cases of violence directed at women and girls through the network, and it was found that:

- $25 \%$ of women between the ages of 25 and 34 were abused in the network, with $66 \%$ of women being sexually assaulted.

- Nearly half of the women who experienced online violence $(49.5 \%)$ reported that they received responses regarding their sexuality regardless of the relevant content (Israel Internet Association, 2014). 
Table 1 - Victims of cybercrime aged 20 years and over by type of violation - 2018 census (in percentages).

Threats $.6 .5 \%$

Sexual harassment. $.11 \%$

Extortion crime against theft or publication...12\% plagiarism and theft. 25 .

Computer(virus)

Identity theft and impersonation. $.22 .5 \%$

Other crimes. $.05 \%$

(Central Statistical Organization, 2019)

This study recommends that $11 \%$ of all violations were sexual harassment online. .It requires attention to reduce it and address the reasons for this (Israel Internet Association,( 2019).

\section{National Council Study - Child Welfare (2016)}

This study aimed to present the increase in sexual harassment, which occurred from the continuous use of the network, where the main crime was sexual harassment. From 4\% in 2006 to $15 \%$ in 2015 , to $16 \%$ in 2016 , to $17 \%$ in 2017 (Alon, 2019).. Against minors and minors (12-17 years).. My expulsion is proportional between violations and years, so these recommendations The study is expedited to develop a plan to stop this escalation in sexual harassment.

\section{Study of Sheikh Abdul Rahman (2009)}

This study aimed to understand and analyze the problem of verbal sexual harassment in all technological ways and means, its prevalence, and its connection with institutions and social systems through a critical view of specialists and counsellors. This study recommended the development of legislation penalizing verbal sexual harassers up to prison. 
Percentage of sexual harassment among all sexual crimes, under the age of 18 20

18

$\overline{16}+\bar{*}+\ldots$

12

$-$

10

08

06

04

02

00

20062008

2018

Percentage of sexual offenses out of the total number of complaints - under the age of 18 Linear (the percentage of sexual offenses out of the total number of complaints) - under the age of 18 from 06 to 18.

\section{Keren Study (2020).}

This study aimed to explain what the Corona crisis caused in confining young people, male and female students, to homes, and as a result - the cessation of sexual abuse in the physical space. Which made social media a place of refuge, even for those who weren't quite active in it.

Barkan study (2020) aimed to direct the gaze, not only to students, but also to outsiders who are looking for easy prey, and who break into classrooms in Zoom. This study recommended a technology that prevents intruders from entering through Zoom.

Almakawi study (2016) was carried out under the supervision of the United Nations This study aimed to show the severe moral and physical impact of the victim, where the Harass map indicated that $99.3 \%$ of the sample of women and girls who were studied had been subjected to verbal sexual harassment, and urban sexual harassment with a higher percentage than rural cases. This study recommends rapid psychological treatment for those who have been subjected to verbal sexual harassment.

\section{Shehadeh Study (2018)}

It aimed to show the results formed and resulting from the moral and psychological beating of the victim, especially the impact of verbal sexual harassment on the 
economic side. It recommends raising women's awareness and awareness, encouraging them to submit a complaint to the appropriate addresses, and breaking down the barriers preventing the complaint from being communicated.

\section{Aldwi Study (2017)}

It aimed at how the risk of women being exposed to verbal sexual violence via the Internet exacerbated in the time of the Covid-19 epidemic due to stress and tension, the disintegration of social and protection networks, loss of source of income and reduced access to services. This study recommends allocating sufficient resources for the necessary services, and exploring shelters for women and girls who request this for their protection - a sheltered home.

\section{Commenting on previous studies:}

The researcher wanted to know what was previously written on the subject of verbal sexual harassment, so he reached some sources with the aim of enriching the theoretical numerator on the subject and benefiting from it, to be a general and rich stock for comparing the results of studies among themselves, and also with the results of this study, the study (Barkan, 2020) and ( Aldwi, 2017) talked about the Zoom application program during the Corona epidemic, allowing intruders to penetrate it, and dismantling the protection networks. They recommended finding a technique to prevent the entry of intruders, and to house the victims in safe houses. Some research revealed the definition of the phenomenon of verbal sexual harassment (Pressler, 2015) and (Rooney, 2015), Presler defined it as free, anonymous and easy to use, while Rooney defined it as a social phenomenon in every society, where the values of gender inequality are accepted. Pressler recommended the importance of the role of the family, while Rooney recommended introducing the topic to the school curriculum.

As for the study (Shefi, 2019) "Psychological Services Center" clarified to whom the aforementioned verbal sexual harassment is attributed, that it is attributed to both genders and not only to females, and recommended the role of educational specialists in treating this phenomenon. While the study of the Association of Assistance Centers for Victims of Verbal Sexual Abuse (2015) emphasized the role of technology in supporting and facilitating verbal sexual harassment, so it recommended respect for Natural rights and respecting the laws and not violating them. This is also what was recommended by the study of the Israeli Ministry of Defense (2019), which examined the reasons for using the network.

The study of the Israeli Internet Association (2018) showed a statistic of verbal sexual harassment issues, and attached a table to this statistic for the year 2018 and recommended that $11 \%$ of all violations were verbal sexual harassment, which is not a small number and requires a solution. The same topic was addressed by the study of the National Council for Child Welfare (2016), which indicated the increasing percentages, and recommended the development of a plan to stop this spread.

A study (Shehadeh, 2018) and (Makkawi, 2016) dealt with the psychological and moral consequences of the recipients of verbal sexual harassment. Both studies recommend rapid treatment of victims. 
As for the study (Kirin, 2020), it talked about the expansion of the phenomenon of verbal sexual harassment through the network, and its decline in the physical space, the time of the Corona epidemic..it recommends the open discourse. Contrary to the study (Sheikh Abdel Rahman, 2009), which analyzed the problem of harassment, but recommended imposing penalties up to imprisonment.

Limitations of the study: (Limitation of research)

Objective limits: It is represented in standing on the literature related to the variables of the study (educational specialists, verbal sexual harassment, economic and psychological effects).

1- The study may be recent, and therefore I did not find many sources (books) talking about it.

2- The spatial boundaries of this study: educational specialists in the city of Nazareth in the Lower Galilee, northern Palestine (currently Israel).

3- Time limits for this study: June, 2021.

4- Procedural determinants: They are the terms that the researcher presented procedurally, according to the context in which they were used.

5- Human determinants: selecting 30 educational specialists and mentors as individuals for the research sample.

The results of this study can be generalized in light of the following limitations:

The validity and reliability of the study tool.

The honesty and seriousness of the sample members when answering the questions.

The study population and the sample drawn from it.

\section{Terminology of study:}

Verbal sexual harassment over the network: The so-called electronic harassment, harassment from afar, is a group of word forms that lead to harassment or an unwanted act of the verbal sexual type, and it is an illegal negative behavior that includes sexual and verbal sexual innuendos (Sulaiman, 2018). The term sexual harassment, relatively new, was used in a 1973 report by Mary Rowe for the Massachusetts Institute of Technology. This term has become familiar after it was considered a taboo.

Educational specialists: The psychological or educational specialist is a person who specializes in interpreting human behavior through four aspects: building trust, guidance within a planned program, cooperation and counseling, and finally coordination, i.e. the process of leading, organizing and managing the psychological counseling program (Sulaiman, 2018).

What educational specialists do is a conscious, constructive and planned process, aimed at helping and encouraging the individual, to know himself and understand himself and study his personality physically, mentally, socially and emotionally, and be aware of his experiences and identify his problems and needs, and know the opportunities available to him, and to use his potential intelligently to the maximum extent possible, and that He determines his choices, makes his own decisions, and solves his problems in light of his own knowledge and desire.

ראש הטופס 
Study Methodology: The researcher chose the qualitative (qualitative) survey method, which depends on collecting data and information about the phenomenon, within a certain time. Then, these data and information are analyzed and interpreted, in order to reach results, and contact is made with people who possess information that will benefit the researcher in studies based on this type.

\section{The study sample and its population:}

The researcher chose a random sample by registering the names of 30 educational specialists and counselors from various schools and educational institutions in Nazareth, out of the 150 study population, or $20 \%$. The following table (1) shows the distribution of the study sample and its population according to the independent variables:

\section{Table (1)}

Distribution of the study sample according to its independent variables

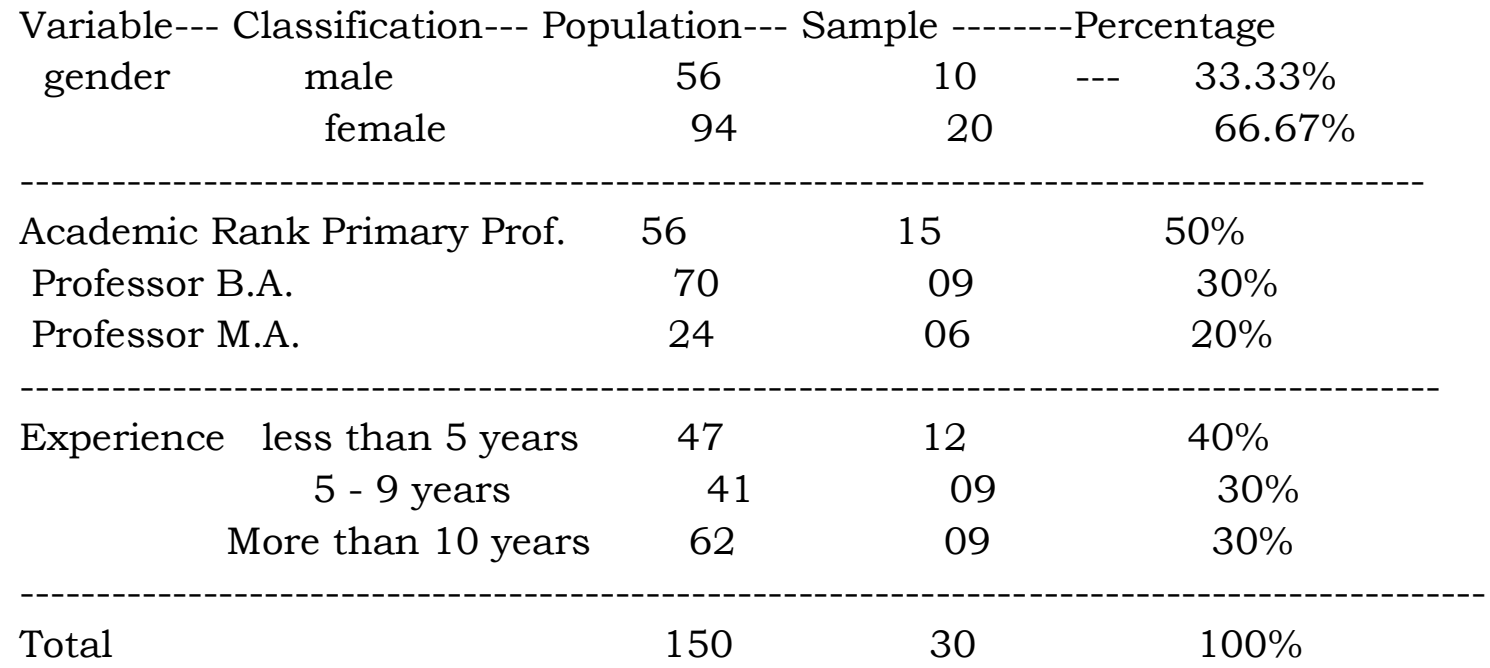

\section{Study tool:}

The researcher used the semi-structured interview (open) as a tool for the study, and the questions were prepared, which were divided into two parts: the first includes questions about the reality of the phenomenon and its causes, and the second includes the mechanisms of reducing it. These questions were then presented to arbitrators with expertise and experience in constructing interview questions in the humanities.

\section{Validity of the tool:}

The validity of the interview questions was confirmed by presenting the study tool to a group of specialized arbitrators, their number reached (7) arbitrators. verbal sexual and the second in the field of mechanisms to limit the spread of this phenomenon). Also, (3) questions were deleted from the field of mechanisms to limit the spread of this phenomenon, so that the final number of questions became (4) comprehensive, central and clear questions, based on previous studies and theoretical numerators. 


\section{Tool stability:}

1- Ensuring the stability of the study tool in two ways: the first is by using the method of repeating the interviews again after an interval of one week, and then calculating the Karl Pearson correlation coefficient through which we can know the relationship between two variables (independent variable and dependent variable), and their answers in both times. The correlation coefficient is between (0.95), but the value of the correlation coefficient should not exceed 1 True.

2- Calculation of the reliability coefficient (Cronbach's alpha), which is a single number or scale that measures the degree of stability and sincerity of questions, and takes values ranging between (0) and (1), where the value of the reliability of the questions about the causes of the phenomenon is (0.874), and the total degree of the field of limiting mechanisms (0.895), which is a high percentage indicating the consistency between the questions.ראש הטופס

Results:The results of the first central question, which states: What is the reality of verbal sexual harassment among high (Tawjihi) students in Nazareth from the point of view of specialists and counselors?

$80 \%$ is an immoral pornographic verbal phenomenon that exists in the student community.

$10 \%$ of their behavior shows that they do not understand the phenomenon.

$10 \%$ is an instinctive trait, but it is harmful.

\section{Table (1)}

Answers-------------------------- Number of sample-

\section{Percentage}

It is an immoral pornographic verbal

phenomenon that exists in the student

community.

24

$80 \%$

From their behavior it is clear that

they do not understand the

phenomenon .

03

$10 \%$

Is an instinctive trait, but it's harmful

03

$10 \%$

Total $=$

30

$100 \%$

It turned out to us that all members of the sample confirmed the existence of this phenomenon, as confirmed by the study (Shehadeh, 2018), but each group linked its existence in a different way, as most of the sample members confirmed that it is a bad phenomenon that undermines the principles of the conservative Arab society. The results of the second central question, which states: What are the causes of verbal sexual harassment among high (Tawjihi) students in Nazareth from the point of view of specialists and counselors?

$30 \%$ as a result of family disintegration, overcrowding and oppression.

$30 \%$ lack of education, lack of morals and low films. 
$20 \%$ see it as a result of the growth of hormones, but it seriously harms natural rights.

$10 \%$ see it as a result of the corona epidemic and home confinement.

$10 \%$ of specialists see it as a way to satisfy instincts.

\section{Table (2)}

Answers-

Number of sample mem. Percentage

As a result of family disintegration,

crowding and repression.

09

$30 \%$

Lack of education, lack of morals and low movies.

09

$30 \%$

Resulting from the growth of

hormones, but it seriously

affects the natural rights.

$20 \%$

As a result of the corona

epidemic and home confinement.

$10 \%$

A means to satisfy instincts

and physical needs.

$10 \%$

The researcher attributes that the most important reason is the disintegration of the family bond, as stated in the study (Pressler 2015).

It appeared to us that the disintegration of the family, and the lack of education are the main reasons for the phenomenon of sexual harassment, as appeared in the study (Kirin, 2020). However, a smaller group attributed its causes to the epidemic of Corona and home confinement, and as a means of satisfying instincts.

The results of the third central question, which states: What are the effects of verbal sexual harassment among high (Tawjihi) students in Nazareth from the point of view of specialists and counselors?

$20 \%$ increase in the rate of environmental pollution, and difficulty in concentrating.

$40 \%$ Disorders in behavior, eating, tiredness and fatigue.

$30 \%$ panic attacks and drug abuse.

$10 \%$ loss of self-confidence and self-esteem

Table (3)

Answers-

Number of sample mem.

Percentage

A high rate of environmental

pollution, and difficulty in 
Behavioral disturbances, eating, tiredness and fatigue.

Panic attacks and drug abuse.

Loss of self-confidence and self-esteem.

03

The researcher attributes that the effects of this phenomenon are many and varied, some of which are visible and most of them are hidden.

The repercussions and effects of the phenomenon, as shown by the third question, are mostly manifested in behavioral disorders, fatigue and fatigue, as appeared in a study (Makawi, 2016). Whereas, smaller groups emphasized panic attacks, drug abuse, environmental pollution, and a loss of self-confidence, which imposes itself on all aspects of life for the online harasser.

The results of the fourth central question, which states: What are the proposed mechanisms to reduce verbal sexual harassment among Tawjihi students in Nazareth from the point of view of specialists and counselors?

$10 \%$ Create an environment that rejects verbal sexual harassment, through awareness-raising and education.

$20 \%$ impose the most severe penalties on verbal sexual harassers, even imprisonment.

$50 \%$ of education, education and open discourse in schools.

$20 \%$ Allocating ongoing budgets for lectures and workshops for parents and the community.

ראש הטופס

\section{Table (4)}

Answers Number of sample mem. Percentage

Creating an environment that

rejects verbal sexual harassment, through awareness-raising and education.

$10 \%$

Severe punishments for verbal

sexual harassers, even

imprisonment.

$20 \%$

Education, pedagogy and open

discourse in schools. 
Allocating ongoing budgets for

lectures and workshops for

parents and the community.

$20 \%$

Total

$100 \%$

From the fourth question, it becomes clear to us that half of the sample members confirm that the best mechanism for treating this phenomenon is education, as this appears in most of the literature and in the study (National Council for Child Welfare - 2016), and open discourse as shown in the study (Kirin, 2020). The researcher attributes that all the mechanisms can affect the process of preventing the phenomenon in different proportions, but they are unified and affect effectively.

\section{Analysis of the results}

The answers to the first question revealed that sexual violence in general, and sexual violence in the network in particular, violates the right to dignity and the right to life and security. And all the participants in the interviews confirmed the reality of sexual harassment through the network. The Israel Police find it very difficult to eradicate this phenomenon. The general attitude to this phenomenon is clearly lacking, because most women do not file a complaint with the police about harassment - for fear of "victim blaming" (a process in which society blames the victim for the crime, rather than the person who offended her).

As for the second question about the mechanisms of limiting this phenomenon, the focus was on educational institutions. Officials are the ones who work to achieve the expected results by virtue of their position, and they are expected to provide a high service and achieve the goal of reducing this phenomenon by monitoring the budgets required in education to raise and improve awareness. Students and parents to prevent the spread of this phenomenon.

The authority should also assist educational institutions and push them to adopt methods, and support faculty members, workers and the uneducated to address this phenomenon.

\section{Recommendations}

According to the first question, and as it became clear from the interviews, that there are not enough budgets to hold continuous courses, workshops and lectures throughout the year, which makes eliminating this phenomenon impossible. So :

1- The government and the Knesset must provide sufficient budgets to solve the problem.

2- An educational and legal (political) monitoring authority should be established to raise awareness and deter, because this phenomenon undermines the principle of the rule of law in this country, people put their freedom above the rights of victims, and thus violate the system, social laws and network laws.

3- Introducing this sensitive topic to the curriculum to be discussed in a proper manner, because it will enter the educational and societal field without permission. 
Only when the public understands how aggressive, dangerous and taboo this phenomenon is, will it agree to fight it - then change will occur, and the phenomenon will be reduced.

Depending on the second question, women and girls are encouraged to attend lectures on the effects of verbal sexual harassment, to educate them and strengthen their personalities, to confront any verbal sexual harassment.

Based on the third question: Issuing a booklet to explain the effects of verbal sexual harassment, and holding discussion panels about what it says.

According to the fourth question: stopping this phenomenon does not come with imposing penalties because it is temporal and not internalized, so the most successful way is to internalize the harmful effects of this phenomenon through education.

\section{Arabic references:}

Sheikh Abdul Rahman, Saleh. (2009). Sexual Harassment: Its Causes, Repercussions, Confrontation Mechanisms. Cairo University.

Ihab, Al-Hadary. (2010). The Alternative Space, Political and Social Practices of Arab Youth on the Internet. Center of Arab Civilization, Giza: Egypt.

Al-Makkawi, Hana. (2016). Sexual harassment: a behavioral disorder supported by a societal imbalance. Cairo Egypt.

Suleiman, Abdel Alim Mahmoud. (2018). Electronic sexual harassment - a study of patterns and motives. Cairo Egypt.

Shehadeh, Nardin (2018). On Verbal Sexual Violence against Women. Haifa: Israel.

Abdel-Aty, Amr. (2016) Sexual harassment from the street to social networks. The Arab Forum for Social and Human Sciences, The Future for Research and Advanced Studies: Abu Dhabi.

Fadela, Hanash, Muhammad bin Yahya Zakaria, (2011). School and vocational guidance and counseling from the perspective of the new education reforms. El Harrach: Algeria.

Farraj, Othman, Abdel Latif Hammouda, (1961). Guidance and psychological counseling meaning and importance. Ministry of Higher Education, Southern Region: General Administration for Research, Central Library: Gaza.

Gibran, Nora. (2014). "Does electronic sexual harassment compete with direct sexual harassment between the harasser and the victim?" Al-Sharq alAwsat newspaper, article published on Monday, September 22, Riyadh: Saudi Arabia.

Hana, Al-Ramli (2015). Internet Heroes.. How to protect yourself from cyberbullying and online sexual harassment. Azma House for Publishing and Distribution, first edition: Amman, Jordan.

Foreign references: (in English)

Agnew, R. (2006).General strain theory: Recent developments and directions for further research. In F.T. Cullen, J. Wright, \& M. Coleman(Eds.), Advances in criminological theory, taking stock: The status of criminological theory.(pp.101-123).New Jersey: Transaction Publishers. 
Barak, Azy.(2005). Sexual Harassment on the Internet, Social Science Computer Review, Vol. (23), No (1), 77-92.

Dana, Hysock (2006): Fan bet Ween friend? How peer culture influent cesadoles cenlsinrerpredtins of and responses to peer sexual Harassment in high school, ph. D, university of Delaware.

Dziech, Billie Wright, Weiner, Linda (1990): The Lecherous Professor: Sexual Harassment on Campus. Chicago Illinois: University of Illinois Press.

Jo Celyn, Handy,(2006). Sexual Harassment in small-Town ,New Zealand: Aaulitative study of three Contrasting Organizations, Gender ,Work and Organization, Vol (13) NO(1), January.

Pesin, G., Lipshits-Braziler, Y., Amram-Vaknin, S., \& Tatar, M. (2018)., Identifying patterns of seeking and providing help online among adolescents in Israel., Paper presented at the International Conference on Counseling Psychology, London, United Kingdom.

Schenk, Samantha .(2008). "Cyber-Sexual Harassment: Te Development of the Cyber Sexual Experiences Questionnaire," McNairm Scholars Journal: Vol. (12), no (1), Article(8).

Yaakov Ophir, Christa S.C. Asterhan, Baruch B. Schwarz,(2019). The digital footprints of adolescent depression, social rejection and victimization of bullying on Facebook, Computers in Human Behavior 91, 2019-02,p. -62 71

\section{Hebrew references}

Ofir Y., Rosenberg h. And Astrakhan K. (2017)., "If only the walls (on Facebook) could speak": Detecting distress and caring for youth through the social network, in: Schwartz B., Rosenberg h. And Astrakhan K. (Editors). "Education walls have fallen in the net": teachers, students and social networks. Tel Aviv: Exemplary Institute.

Heiman, Tali. (2012). Violence and cyberbullying - a snapshot. Echo of Education: Vol. P.Z., Issue No. 06

\section{Online references (from the network)}

Central Bureau of Statistics (2019) "First results of the 2018 Personal Security Survey:"22.10.2020

https://old.cbs.gov.il/www/hodaot2019n/18_19_199b.pdf

National Council on Child Welfare (2016). Statistical summary "Children in Israel 2016

https://fs.knesset.gov.il/20/Commanies/20_cs_bg_367605.pdf: "Data

10.21.2020

3.National Council for Child Welfare (2017). Statistical Abstract of Children in Israel 2017 - "Data Set" https://www.children.org.il/wp-:.21.10.2020 content/uploads/2018/08/pdf_merged.pdf

National Council for Child Welfare (2019), Statistical Abstract 'Children in Israel 2019 - Content / Uploads / 2020/02/\% D7\% 94\% D7\% 9E\% D7\% 95\% D7\% A2\% D7\% A6\% D7\% 94 